\title{
Cloud Computing an Emerging Tool to Survive E-Business Especially Small and Medium Sized Business
}

\author{
Dr. Pragati Saxena \\ Department of Computer Science, UP Technical University, Hierank Business School,Sector 62, Noida, UP
}

\begin{abstract}
During last several decades the advancement in Information technology has given a boost to business enterprises to generate tremendous amount of data and applications in many ways. To process such applications an enterprise requires more powerful computing infrastructure which sometimes increases the operational costsfor the enterprise. The paper focuses on the challenges that SME's face while adopting E-business and also on probable solutions in the form of cloud computing. Cloud computing is a subscription-based service which allows its user to obtain networked storage space and computer resources based on "Pay as service". The phenomenon of cloud has changed the scenario of online business especially the small and medium sized firms which need not build a costly infrastructure, instead they can pool cloud resources at a lesser cost. Pooling resources simplifies business IT infrastructure and reduces their operational cost.
\end{abstract}

Keywords: E-Business, Brick and Mortar, Cloud Service Providers, SAAS, PAAS, IAAS

\section{Introduction}

The scope of IT has crossed the geographical boundaries and helps in boosting the economy of India. IT is a major contributor of revenue and employment generation and has given many opportunities to entrepreneurs. SMEs contribute significantly to the economy of a country, representing around $90 \%$ of all businesses, and providing the main source of jobs and income.

An important product of IT that has revolutionized the entire scenario of business industry is E-Business i.e. performing business electronically. E-business has given new dimensions and opportunities for exploring new ventures. The objective of E-Business is to perform trading, marketing and servicing of products via computer networks [1]. It has changed the way firms perform their operations, communication, promotions of the products they produce and restructure their business processes to deliver tailored product(s)to the final customers. Many small and medium sized firms are trying their luck through e-business as it is easier and cheaper compared to Brick and Mortar Business.

But as we know that every coin has two sides, in the same way e-business has its own opportunities and challenges.

There are many challenges in e-business too. In this paper we will focus on challenges that influence the growth of ebusiness and changes its focus from core competencies to resource requirement.

The paper focuses on the infrastructure issues that an enterprise faces while running the e-business. Enterprises are putting their efforts in building an infrastructure for performing a business. But too much emphasis on resource requirements has shifted their focus from gaining competitive advantage. Also they can ${ }^{\text {ee }}$ afford to make heavy investments in infrastructure and IT as their utilization is less compared to its cost. So they have to maintain a balance between smooth operations and stable performance.

The paper highlights an important technology of "Cloud Computing" that has changed the scenario of doing business and helped small and medium sized firms to reduce their cost of operations.

The paper explores the importance of cloud computing in ebusiness in dealing with the challenges of operating cost, backward integration, and lack of experienced resources. Also discusses on how an enterprise can survive through cloud computing, its advantages and its impact on doing ebusiness.

\section{E-Business Challenges}

Electronic Business is quite a buzzword in today ${ }^{\text {ee }}$ s business environment. It is an exchange of goods, services and information between buyers and sellers through electronic means. It includes both the monetary and non monetary transactions. Entrepreneurs are trying to incubate new ideas to create unique and innovative products to have competitive edge through e-business. But doing business using electronic means is not that easy. SME $E^{e e}$ face many challenges while doing their business.

The most important factors to consider are reliability and trust issues. The risk associated with misuse of customer information, frauds, credit card information theft, hacking etc. has shaken the customer trust and holds them from using websites.

E-business sites use online resources and social media to promote their product and services which also gives easy access to cyber attackers to access business information. Ebusiness firms especially the $\mathrm{SME}^{\mathrm{ee}} \mathrm{s}$ which don ${ }^{\text {ee }} \mathrm{t}$ have a robust technological structure becomes the prey of cyber attackers. 


\section{International Journal of Science and Research (IJSR) \\ ISSN (Online): 2319-7064}

Index Copernicus Value (2013): 6.14 | Impact Factor (2014): 5.611

Attackers can divert financial assets, shut down communications among employees or business partners, steal intellectual property, damage an organization "es reputation, or bring e-commerce (or an entire business) to a halt.

Government supports setting up SMEs and takes initiatives, grants and schemes for the technical upgradation and promotion of business, but due to weak technologies and internet crimes, $\mathrm{SME}^{\mathrm{ee}} \mathrm{s}$ are uncertain of utilizing those funds and create a trustworthy environment for the customers.

Other issues that $\mathrm{SME}^{\mathrm{ec}} \mathrm{s}$ face while starting an e-business are lack of resources, the size of the company and the high setup costs.

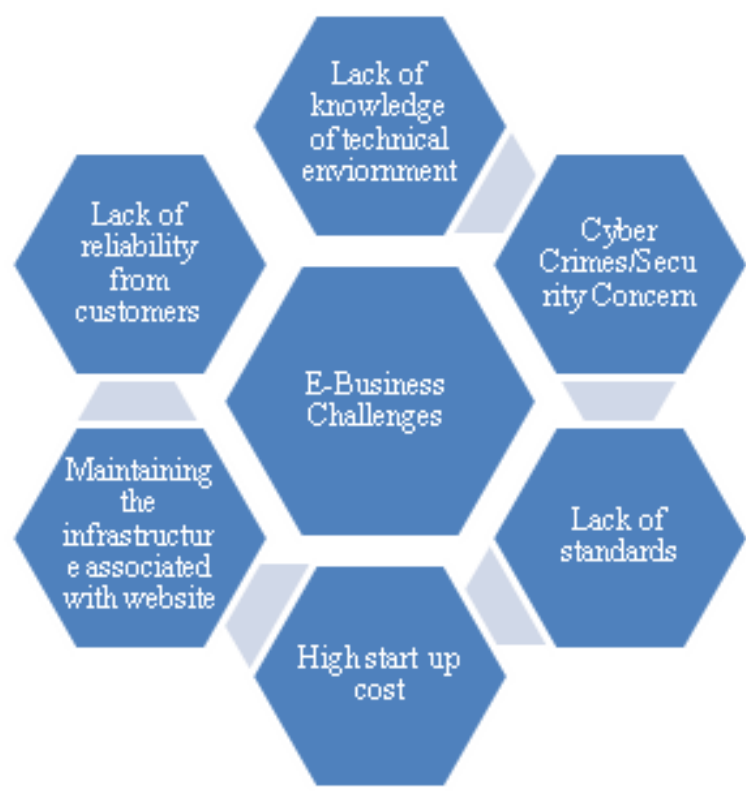

Figure 1: E-Business Challenges

To run a business online, a startup needs many resources for its functioning like data, hardware, software, network and people resources. Many software applications are required to install, their license and regular updates. To execute software applications, a complete hardware infrastructure is required that supports their processing. Data storage space is required to store and maintain the transactions with the customers, important information, business secrets and many more. Many experienced and expert people resources such as analyst, designer, developers, data analysts are required to maintain and upgrade the whole technical infrastructure from time to time. Getting experienced human resources with good technical knowledge of hardware and software is again a big challenge for startups. Network campabilitility is also needed for regular connections.

Firms consumed in business resource settlements are getting less time for research and market study which is further effecting their customer base and revenue generation.

E-business enterprises are looking for a technology which is secured and can support them in reducing their cost. "Cloud Computing" is one such breakthrough technology that helps enterprises to deal with these challenges.

\section{Cloud Computing}

Cloud Computing was proposed by Google in 2007 and its features have influenced the e-business inevitably. Cloud computing is an approach which provides the pool of hardware and software and other computing resources as a service over a network connection [2].

\section{Importance of Cloud Computing in E- Business}

Cloud Computing has an impact on e-business in terms of technology, services and industry Earlier an entrepreneur had to think twice before starting a new business as the money required to buy the resources was high, but now cloud computing has reduced barriers for the startups. Cloud is an alternate to in-house infrastructure that encourages new entrants to conduct their business operations smoothly and their continuity is maintained [3].

Cloud provides various opportunities to startups and large enterprises to control their business cost and stabilize their performance.

Scalability is one of the attractive opportunities given by cloud computing. It means that Enterprise can upscale and downscale its business requirements such as data storage, IT computing resources as and when required. An enterprise need not wait for days for system upgrades or software installation. SMEs are frequently using cloud computing services as it is difficult for them to scale the customer demand and maintain their IT infrastructure accordingly. As the resources are provided by cloud the flexibility of doing business is high. The cloud provides services based on "Pay as you go" basis.

Table1: E-Business Challenges Vs Cloud Solutions

\begin{tabular}{|c|c|}
\hline E-Business Challenges & Cloud Solutions \\
\hline $\begin{array}{l}\text { Resource Requirement varies } \\
\text { with operations }\end{array}$ & Scalability of Business Operations \\
\hline High Cost of Infrastructure & $\begin{array}{l}\text { Infrastructure provided based on } \\
\text { "Pay as Service" }\end{array}$ \\
\hline $\begin{array}{l}\text { Inflexibility of Operations } \\
\text { leads to lack of collaboration } \\
\text { among employees }\end{array}$ & $\begin{array}{c}\text { Flexibility of operations across the } \\
\text { globe }\end{array}$ \\
\hline $\begin{array}{c}\text { Loss of data due to backup } \\
\text { deficiencies }\end{array}$ & Keeps the backup of bu \\
\hline $\begin{array}{c}\text { Lack of technical expertise to } \\
\text { engage in e-business }\end{array}$ & $\begin{array}{c}\text { Technical and system experts are } \\
\text { provided by the cloud }\end{array}$ \\
\hline Reliability and Safety issues & $\begin{array}{l}\text { Provide a trustworthy environment } \\
\text { with latest reliable technology and } \\
\text { protocols }\end{array}$ \\
\hline $\begin{array}{r}\text { Security of ti } \\
\text { privacy }\end{array}$ & Secured Business Transactions \\
\hline
\end{tabular}

With cloud an enterprise need not worry about the installation, upgradation and maintenance of hardware and software resources. As cloud provides its own pool of experts to manage and maintain resources which in turn reduces overall cost and time delays. The hosting team of cloud expertes sork with in-house application developers to design and build cloud-based e-commerce environment that can help organizations to lower their costs and take advantage of new business opportunities. 


\section{International Journal of Science and Research (IJSR) \\ ISSN (Online): 2319-7064}

Index Copernicus Value (2013): 6.14 | Impact Factor (2014): 5.611

Hence cloud hosting is cost effective for startups and keeps its users away from the complexities and expenses of managing the resources. This phenomenon gives the option of renting the physical and virtual resources rather than creating their own.

Data and Applications are available across the globe which enhance the mobility of the employees as they can access the application from anywhere. This helps in collaboration between employees to meet virtually and easily share information in real time and via shared storage. This capability can reduce time-to-market and improve product development and customer service.

Another important advantage of Cloud is Crisis management. In case of natural disasters, power failure or other crisis, important business data remains safe and a backup is maintained [4]. The business can have access to its data irrespective of time and location which minimizes any downtime and loss of productivity. It provides storage space for the entire amount of data to avoid any loss of data due to unavoidable circumstances.

Another important goal of cloud is to provide secured services to e-businesses. Cloud helps in restricting the buyer and seller information and maintains their secrecy. As buyers put a lot of importance on trustworthiness and credibility of sellers, cloud offers a reliable, secured and trustworthy environment.

The objective of cloud computing is reusability of resources. Being in click business it is necessary to invest to maintain IT infrastructure, and as the company grows the investment also increases but due to many factors such as change in demand, sales season and/or in the consumer behavior the invested infrastructure remains underutilized. Cloud computing enables the business to integrate their idle resources with the cloud and rent them to the customers. It reduces the operational cost on one hand and on another hand it prioritizes resource allocation. To sum up, cloud based e-commerce applications enable e-businesses to evaluate opportunities and challenges and respond to them with minimum investments.

\section{A. Types of Cloud Services}

Cloud Computing is an outsourcing service provider that provides a uniform platform that integrates infrastructure and application software. Different types of services that cloud provides to the end users are SAAS (Software as service), PAAS(Platform as service) and IAAS (Infrastructure as a service).

SAAS: SAAS is referred as Software on demand. It is a basic level of cloud service where consumers are able to access software applications hosted in the cloud. The software can be used by both individuals as well as organizations. Google, Twitter, Facebook and Flickr are examples of SaaS which allows its users to access the services via any internet enabled device [5].
Users are renting software applications rather than buying it and keep themselves away from the additional hardware cost, scalability and device compatibility issues.

PAAS: The next level of cloud is referred as Platform as a service. Through this services the users access a platform and environment to build applications and services over the internet. Platform as a Service allows users to create software applications using tools supplied by the provider [5].

IAAS: IAAS is referred as Infrastructure as service. It combines both PAAS as well as SAAS.

The cloud provider provides a virtual infrastructure which includes virtual server space, network connections, hardware, software and other computing resources through which users can build their own IT platform. The provider is responsible for the upgradation and maintenance of all the resources.

\section{B. Example of Cloud Computing}

The biggest and best known Cloud Computing providers include Amazon -E2C, Microsoft - Azure and Google GoogleApps.

E2C is the most successful cloud computing product offered by Amazon which allows users to rent the applications in the setup provided by the cloud. Through cloud users can have access to virtual servers and data storage space. In addition to these core offerings, Amazon offers aSimple DB (a database Web service); a Cloud Front (a Web service for content delivery); and a Simple Queue Service (a hosted service for storing messages as they travel between computers) [6].

Azure from Microsoft is the most upcoming cloud hosting model that gives different set of services to its users. It is a Windows-as-a-service platform consisting of the operating system and developer services that can be used to build and enhance Web-hosted applications [7].

Google Cloud Platform is a suite of products \& services that includes application hosting, cloud computing and database services. Google cloud platform enables enterprises to build, test and deploy applications on highly scalable and technical infrastructure provided by it.

\section{Advantages of Cloud Computing}

As discussed in earlier sections cloud has excelled the computing capacity of $\mathrm{SME}^{\mathrm{ee}} \mathrm{s}$ to a large extent and its advantages are numerous. Its primary goal is to enable the business with the most updated technologies so that the employees can focus on their research, expansion and growth.

Cloud computing helps in reducing e-business operational cost through "Pay as you go" services and expenses on premise installations and device upgrading. 


\section{International Journal of Science and Research (IJSR) \\ ISSN (Online): 2319-7064}

Index Copernicus Value (2013): 6.14 | Impact Factor (2014): 5.611

Cloud computing sets $\mathrm{SME}^{\mathrm{ee}} \mathrm{s}$ free from technical architecture planning, designing and maintaining and enables them to focus on core business capabilities.

Apart from enabling e-businesses with IT resources, platform and infrastructure it offers many other services such as data mining, data conversions in other formats, analyses and maintenance of data. Such activities reduce the cost of data handling tremendously.

Flexibility in work practices, accessibility from any location, reduced cost and improved employee efficiency are some of the other benefits.

Last but not the least the trust factor that $\mathrm{SME}^{\mathrm{ee}} \mathrm{s}$ has for cloud. Users get a reliable and secured environment for their data, transactions and applications. The big players of cloud computing technology like Google, Amazon, Microsoft, IBM and their robust technology are the reason behind this trust.

To sum-up, cloud helps the $\mathrm{SME}^{\mathrm{ee}} \mathrm{s}$ to gain competitive advantage and improves their revenue.

\section{Conclusion}

Cloud computing is a breakthrough technology that has given many advantages to e-business especially to low budget startups. Along with cost savings it has reduced the business risk as there is less need to borrow money for upfront investment in infrastructure.

The arrival of cloud computing is in many respects equivalent to arrival of the Internet in the 1990s and fulfills the maxim prophesized by Google CEO, Eric Schmidt in 2006, when he declared "the network will truly be the computer."

It enables dynamic computing, vast storage, fast and easy access to resources, flexibility in working environment, scalability and information service capabilities. No doubt that cloud gives many computing benefits but as we know every technology has certain loopholes about which the user has to be conscious and extra careful. For example concerns related to data Protection and Privacy legislation and that they are different in various countries.

Cloud providers are putting extra efforts and using protocols and standards to maintain privacy, stability and security of cloud users. But as we know internet can also be used as a platform by attackers to thrive on. Anything that comes under networking is prone to hackers and attackers. Since cloud data exists on internet, privacy and confidentiality of data is a major concerns. Various models and protocols have been designed to deal with this concern and Cloud computing is gradually evolving as a robust option to serve the needs of today's business models in the form of ebusiness.

\section{References}

[1] https://webservices.ignou.ac.in/virtualcampus/adit/course /cst304/ecom1.htm
[2] http://web.mit.edu/smadnick/www/wp/2013-13.pdf

[3] https://www.kpmg.com/IN/en/IssuesAndInsights/Though tLeadership/The_Cloud_Changing_the_Business_Ecosys tem.pdf

[4] https://www.jinfowar.com/security-requirements-cloudcomputing-crisis-management/

[5] http://www.interoute.com/what-paas

[6]Cloud Computing :A practical approach by AnthonyT.Velte,TobyJ.Velte,Robert Elsenpeter, pp 55, 2009

[7] http://www.networkworld.com/article/2175129/cloudcomputing/cloud-computing-12-cloud-computingcompanies-to-watch.html

[8] http://www.hosting.com/top-four-impacts-cloudcomputing-e-commerce-applications/

\section{Author Profile}

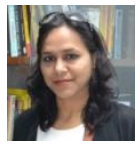

Dr. Pragati Saxena (B.E, MBA, Ph.D.)is a Ph.D from CCS University. She completed her Bachelor of Engineering from „Cummins College of Engineering for Women"e, Pune University (1999) and pursued an MBA from „Bhartiya Vidhyapeeth Institute of Management and Research" Delhi (2001). She is currently working as Asst. Professor at Hierank Business School(HBS), Sec 62, Noida since June 2011. Dr. Pragati has anoverall experience of $11+$ year"s spanning across corporate and academic association with majority of it being in the education domain 